\title{
Evolución del diseño de la Ducati 916 de Tamburini en algunos modelos de motocicletas
}

Jesús Javier Jiménez Galea* Universidad de Málaga

RECIBIDO: 21.12.2015 / ACEPTADO: 17.02.2016

\section{Resumen}

Genio. Esta es la palabra con la que podríamos definir a Massimo Tamburini. Un genio que hacía del diseño de una motocicleta un arte. Suya es la Ducati 916, una de las motocicletas más bellas jamás creada, así como elegante, exclusiva, impactante, etc. Algunos dirían que solo la puede igualar la Ducati Monster 695.

Este artículo recoge algunos de los modelos posteriores a esa obra de arte que fue la Ducati 916 de Tamburini, y la posterior evolución de su diseño en esos modelos.

Palabras clave: diseño, motocicleta, Tamburini, Ducati.

\section{Design evolution of Tamburini's Ducati 916 on some motorcycles models}

\section{Abstract}

Genius. This is the word that we can use to define Massimo Tamburini. A genius who made motorcycle design, an art. The Ducati 916 is his, one of the most beautiful motorcycles ever created, as well as smart, exclusive, stunning, etc. Some people would say the Ducati Monster 695 is the only one that could equalize it.

This article brings some of the following models to that work of art that was Tamburini's Ducati 916, and the following evolution of its design on those models.

Keywords: design, motorcicle, Tamburini, Ducati.

La Ducati 916 hizo su aparición en 1994, con unas soluciones para su diseño que en su conjunto fueron espectaculares, tales como su basculante monobrazo, el chasis multitubular de cromo molibdeno ${ }^{2}$, los 113 caballos (CV) que desarrolla a 9.000 revoluciones por minuto (rpm) ${ }^{3}$ su motor desmoquattro o sus faros delanteros que evocan una mirada felina, entre otros. Su diseño hacía desearla en cuanto la mirabas. Puro arte sobre dos ruedas que enamora. En la fig. 1 se ve la Ducati 998, última evolución del modelo 916 de Tamburini, cuyas diferencias externas con ésta última son mínimas. 

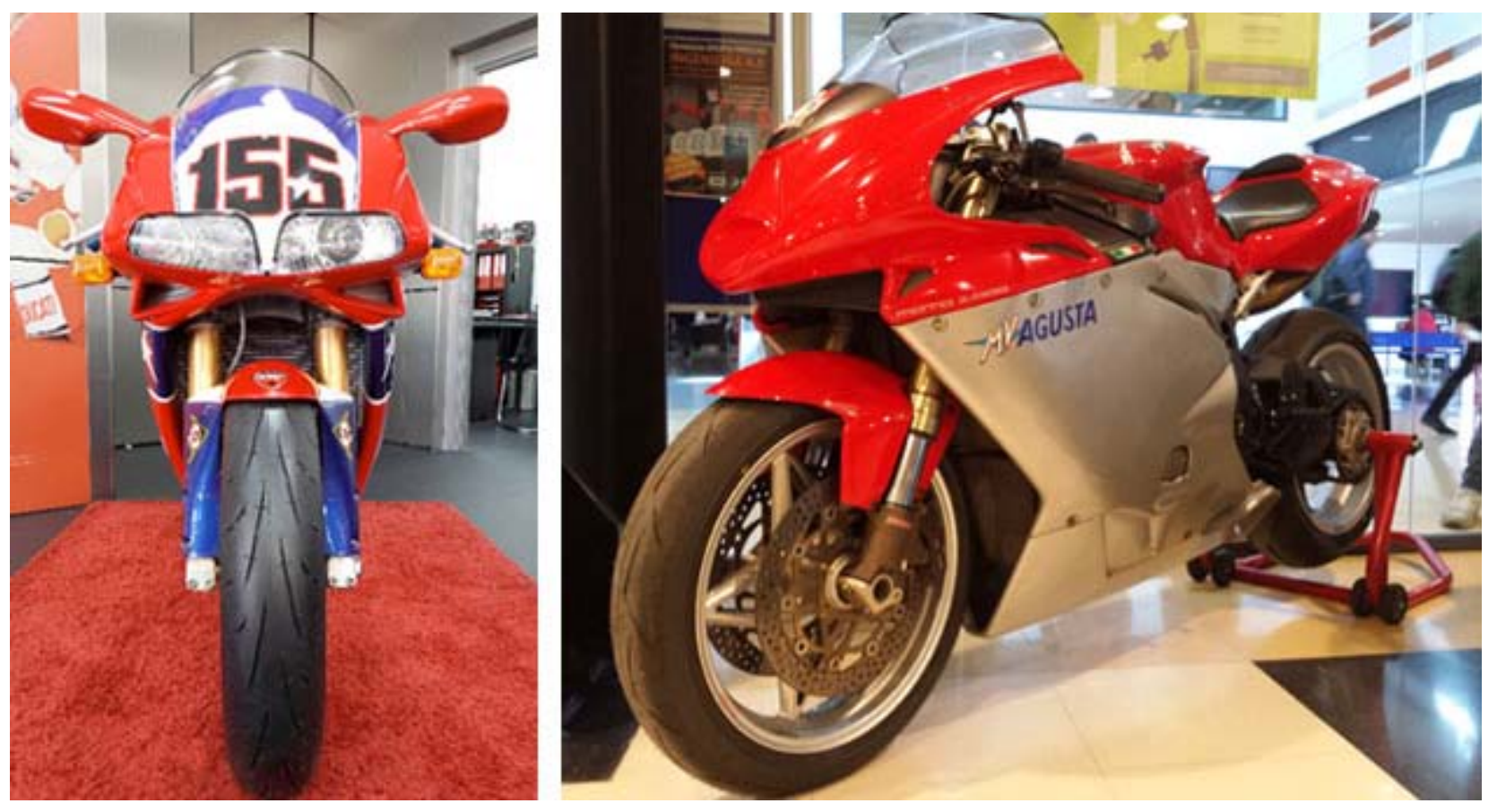

Fig. 1 (izda). Ducati 998.

Fig. 2 (dcha). MV Agusta F4 750 de Massimo Tamburini.

El modelo de Ducati que sustituye a su 916 fue la 996 en el año 1999, variando principalmente entre ambas las pegatinas, las llantas de cinco radios y pocos detalles más. ¿Para qué cambiar la línea de un modelo que era un icono, que se vendía muy bien y que otros fabricantes intentaban copiar?

Antes de ese año de 1999 Massimo Tamburini se había ido con Claudio Castiglioni a MV Agusta, y precisamente ese año Tamburini sacó la que debiera haber sido la evolución de su modelo 916 en la fábrica Ducati: la MV Agusta F4 750, que se puede ver en la fig. 2. O sea, había evolucionado su diseño de la 916, en vez de en Ducati en MV Agusta. A pesar de ser una motocicleta exclusiva, con un diseño muy conseguido, elegante también, y muy bella, no tuvo la F4 el impacto del que sí gozó en el año 1994 la Ducati 916.

Ducati respondió en el año 2002 sacando su modelo 998, con un diseño exterior prácticamente idéntico a la 996, aunque con ligeras modificaciones como la anulación de las pequeñas aperturas laterales del carenado, e incorporando ya los nuevos motores Testastretta (cabeza estrecha). Dentro del modelo 998, una de las versiones que Ducati sacó fue la exclusiva 998 S Ben Bostrom, con una potencia de $136 \mathrm{CV}$. En las siguientes figs. 3 y 4 se ve esta versión, que es la unidad 76 de las 155 fabricadas.

En la fig. 5 se ve perfectamente el basculante monobrazo, en la fig. 6 se aprecian los dos escapes debajo del magnífico diseño del asiento, colocándose en esa configuración para que aumente la aerodinámica de la motocicleta, y en la fig. 7 vemos la culata desmoquattro que llevaba la 916. 

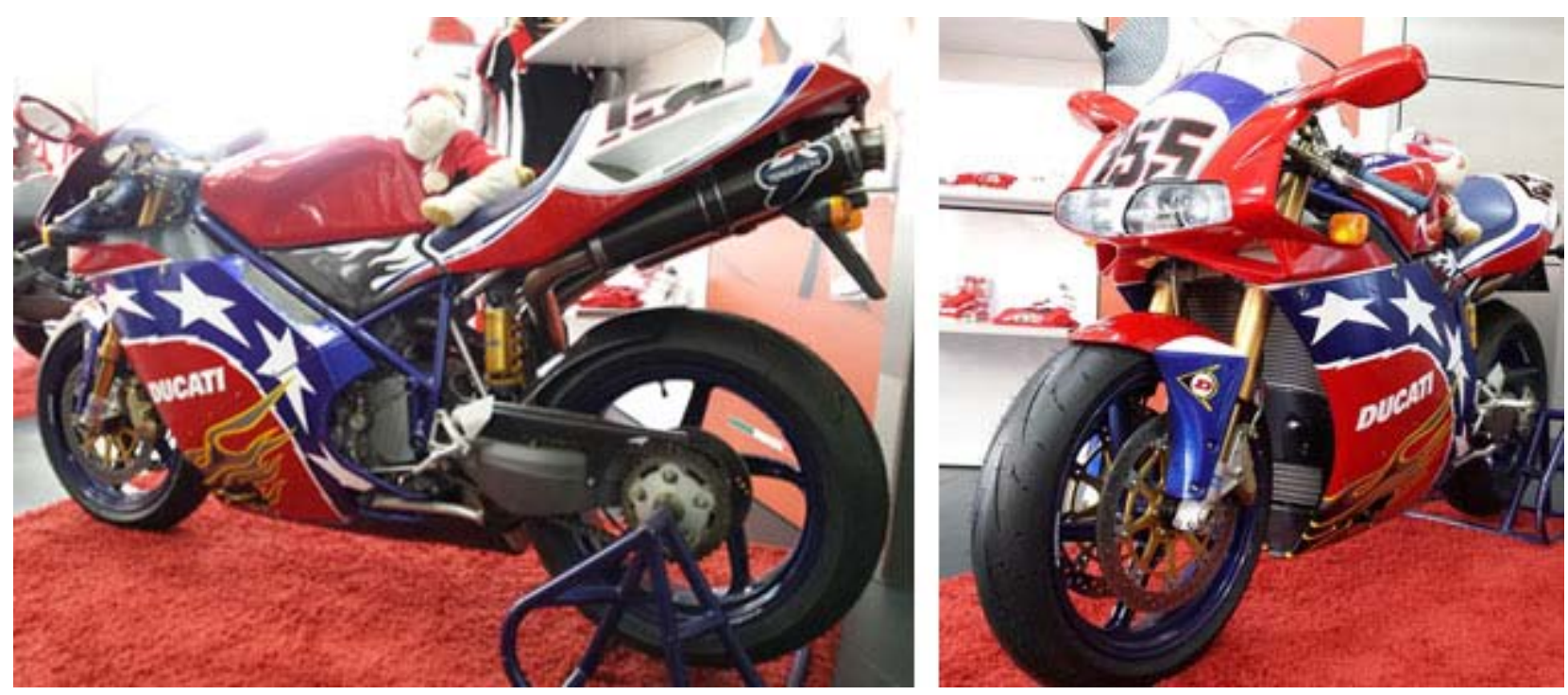

Figs. 3 y 4. Diferentes vistas de la 998 S Ben Bostrom.
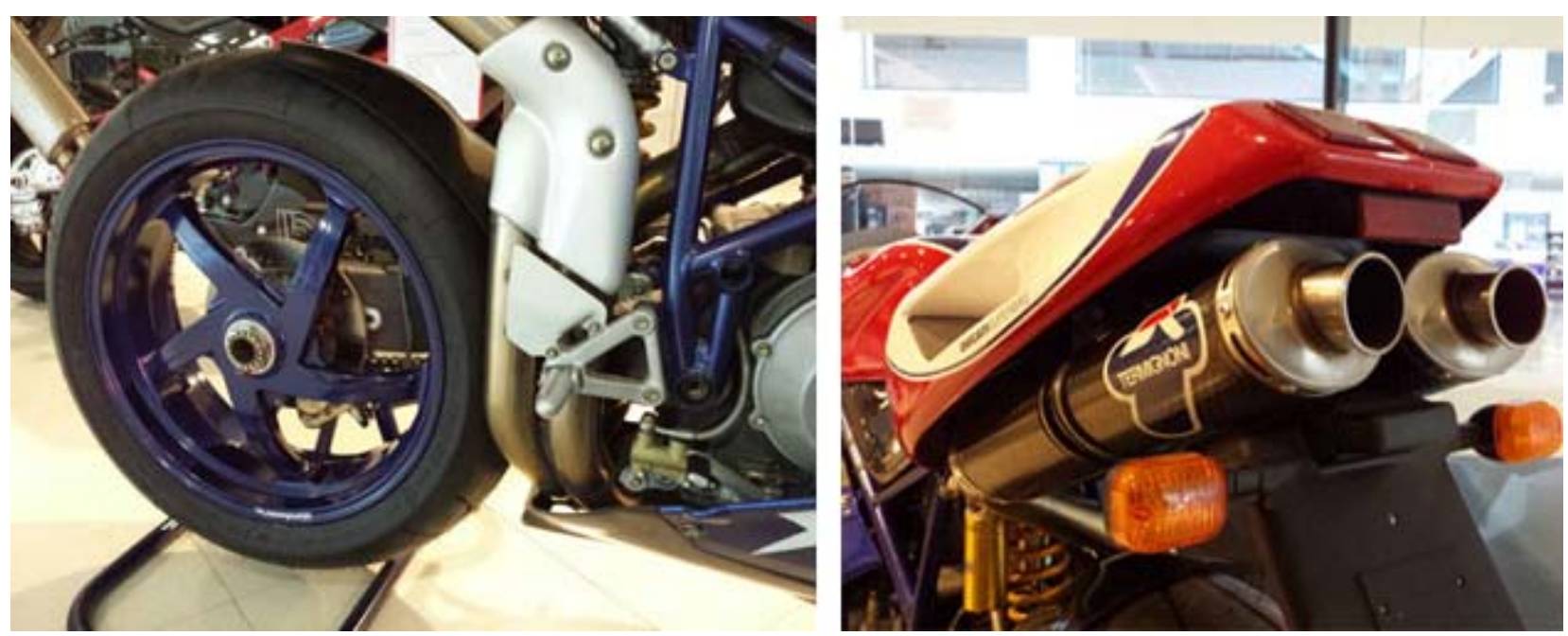

Fig. 5 (izda). Basculante monobrazo de la 998.

Fig. 6 (dcha). Escapes Termignoni debajo del precioso asiento de la 998.

Llegados al año 2003, Ducati intenta crear otro efecto tan rompedor como fue el diseño de la 916, con su nuevo modelo 999, diseñado por el sudafricano Pierre Terblanche. Sin embargo, fue un modelo que no tuvo la aceptación esperada entre los ducatistas y esta apuesta no salió bien, ya que poseía quizás un diseño demasiado adelantado a su año de presentación tachándose de feo. Visto a día de hoy, la percepción ha cambiado con respecto a ella, y a muchos de los que antes no les gustaba el diseño ahora sí. Máxime cuando al no haberlas valorado nadie, cada vez hay menos porque se destruyen y consecuentemente su valor se incrementa.

En la siguiente fig. 8 se puede ver una 999 modificada con los mejores componentes que se podían adquirir tanto para su motor, que desarrolla $180 \mathrm{CV}$, como para su parte externa que realzan aún más su diseño, entre otras cosas por el uso de la fibra de carbono. En la fig. 9 se puede apreciar el gran escape alojado debajo del asiento. 

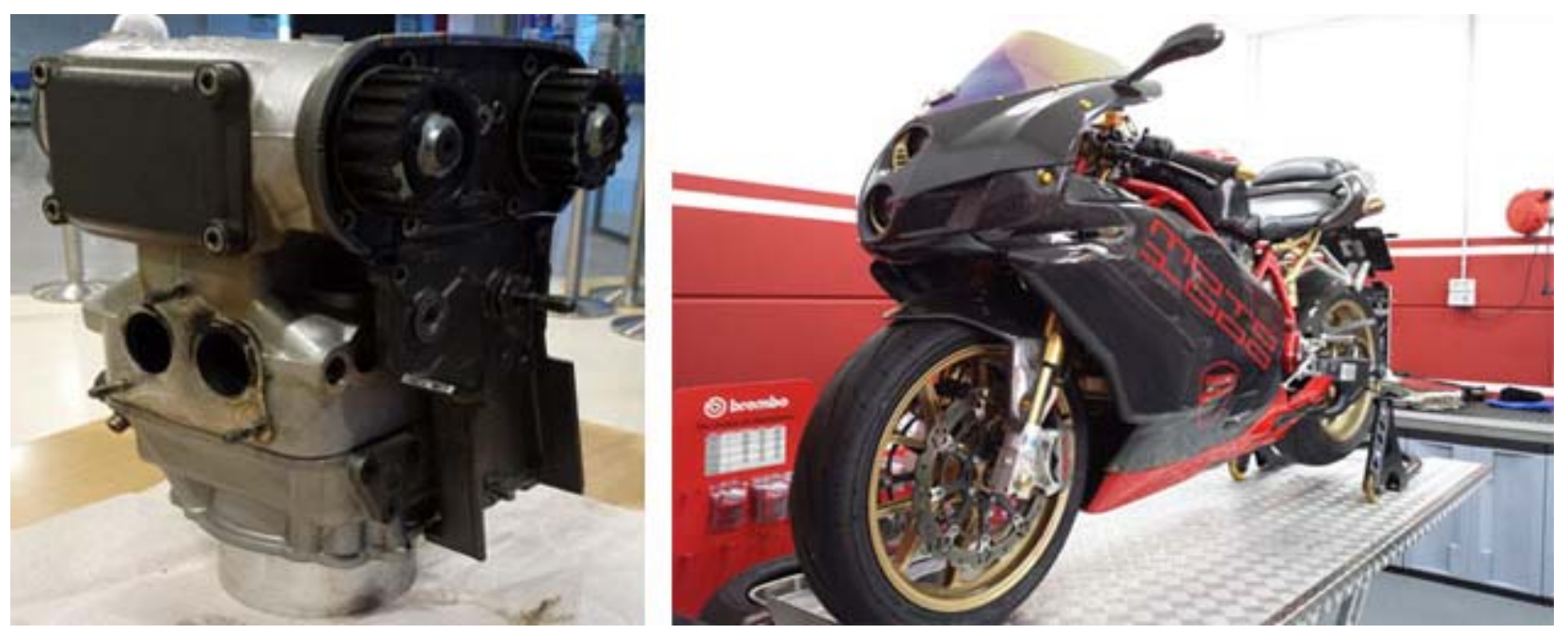

Fig. 7 (izda). Culata desmoquattro de la 916. Fig. 8 (dcha). Vista de la Ducati 999.

En ambos lados del carenado se aprecian unos deflectores cuya misión es dar estabilidad en las rectas. En la fig. 10 se ve el frontal de una 999 del año 2003 y en la fig. 11 un frontal del año 2005. Se aprecia que se han eliminado los conductos triangulares superiores, por el que entraba aire destinado en un inicio para evitar el empañamiento de los relojes, así como para evitar vacíos detrás de la cúpula. Se dice que al tapar esas entradas se conseguía aumentar la velocidad en 7 $\mathrm{km} / \mathrm{h}$, que es una cantidad considerable. Otro detalle de la evolución de los frontales del 2003 al 2005 es la eliminación del tornillo inferior de la cúpula porque partía el plástico en esa zona, subsanándose con la colocación de un tornillo a cada lado un poco por encima de esa zona inferior que rompía, como se aprecia perfectamente en la fig. 11 del frontal del año 2005. El diseño no deja de evolucionar, pero siempre en la búsqueda de unas líneas armoniosas y llamativas que atraigan todas las miradas a la vez que consiga mejorar mecánicamente el conjunto de la motocicleta.
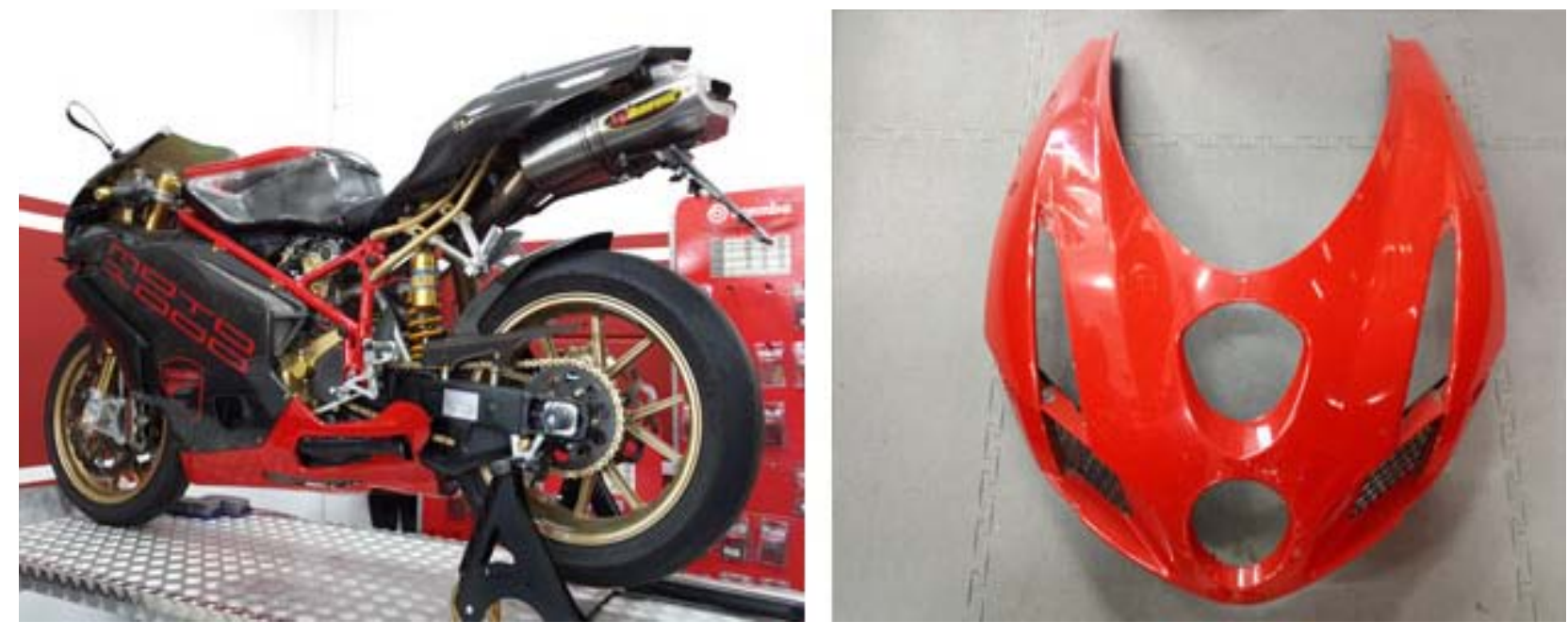

Fig. 9 (izda).Vista lateral izda. de la 999 donde se aprecia el escape alojado debajo de su asiento . Fig. 10 (dcha). Frontal de la 999 del año 2003.

En la siguiente fig. 12 se ve un frontal Performance del año 2003, en el que se puede observar cómo elimina los triángulos superiores para las tomas del aire, pero aún no modifica la colocación del tornillo inferior. 
La 999 también fue uno de los modelos precursores de la parte trasera de los asientos minimalistas que actualmente están tan de moda. Es otro detalle con el que se aprecia que este modelo se adelantó a su tiempo.
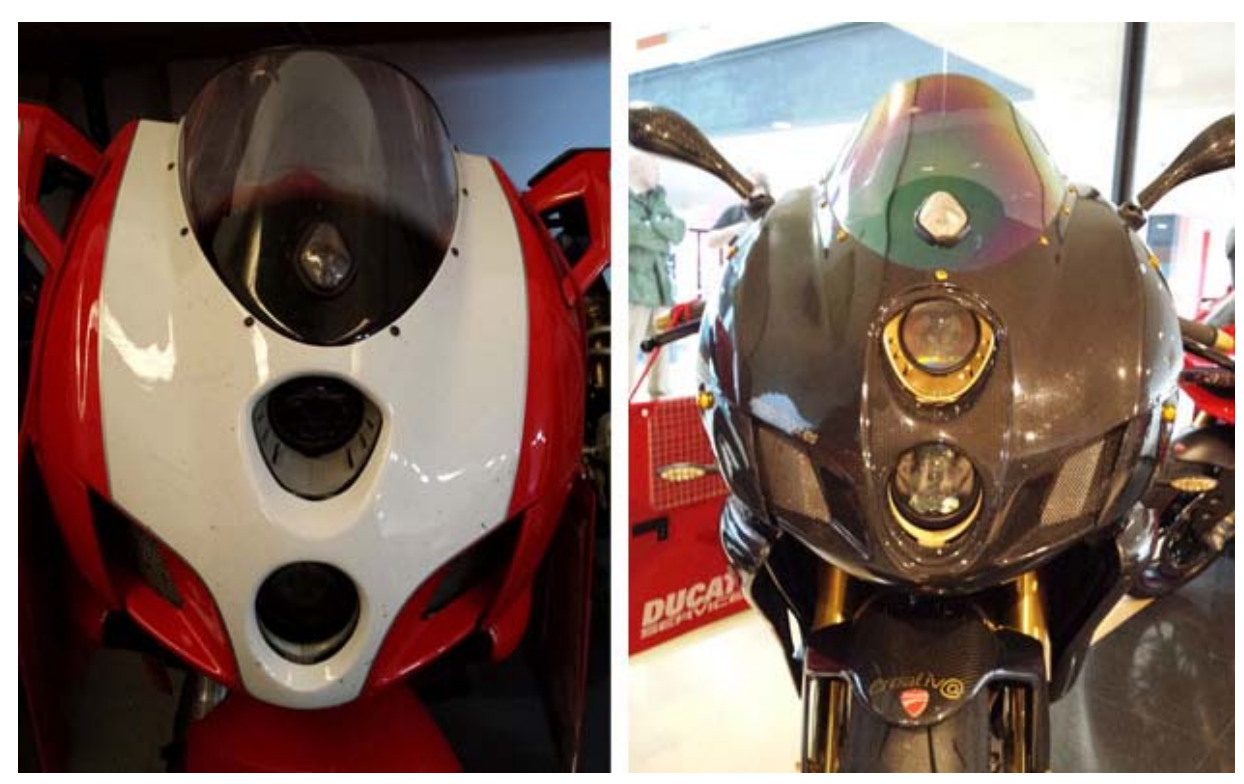

Fig. 11 (izda). Frontal de la 999 del año 2005.

Fig. 12 (dcha). Frontal de la 999 Performance del año 2003.

La sustituta de la Ducati 999 llegó en 2007 con la 1098, y es considerada una mera excusa para salvar las críticas al diseño de la 999. Se puede deducir que fue una mezcla del diseño de la 998 con la MV Agusta F4 750 de Tamburini, por lo que el diseño resultante no llegó a convencer nunca a los ducatistas puros. A pesar de ésto, el diseño es una belleza, tal y como se puede ver en la fig. 13 de su lateral y en la fig. 14 de su frontal.

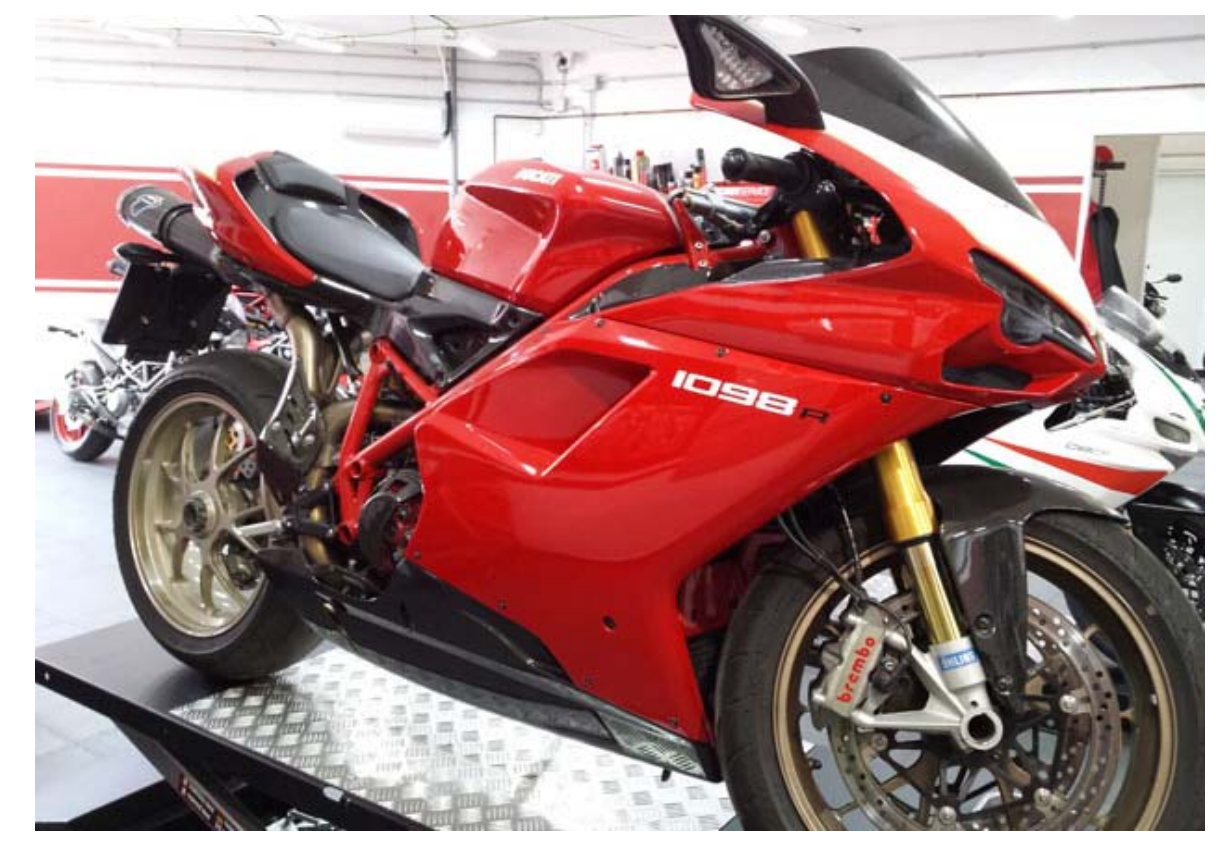

Fig. 13. Vista lateral de la Ducati 1098.

Para ver la similitud con la F4, las imágenes siguientes de las partes traseras de los asientos de ambas motocicletas hablan por sí mismas. En la fig. 15 se tiene la parte final del asiento de la 
1098, y en la fig. 16 se ve la correspondiente de una F4 1000 del año 2015, que apenas tiene variación en el diseño con el original del año 1999. Para ver la similitud con la 998, entre otros detalles, basta con fijarse en los focos delanteros de ambos modelos, y comparar su parecido.
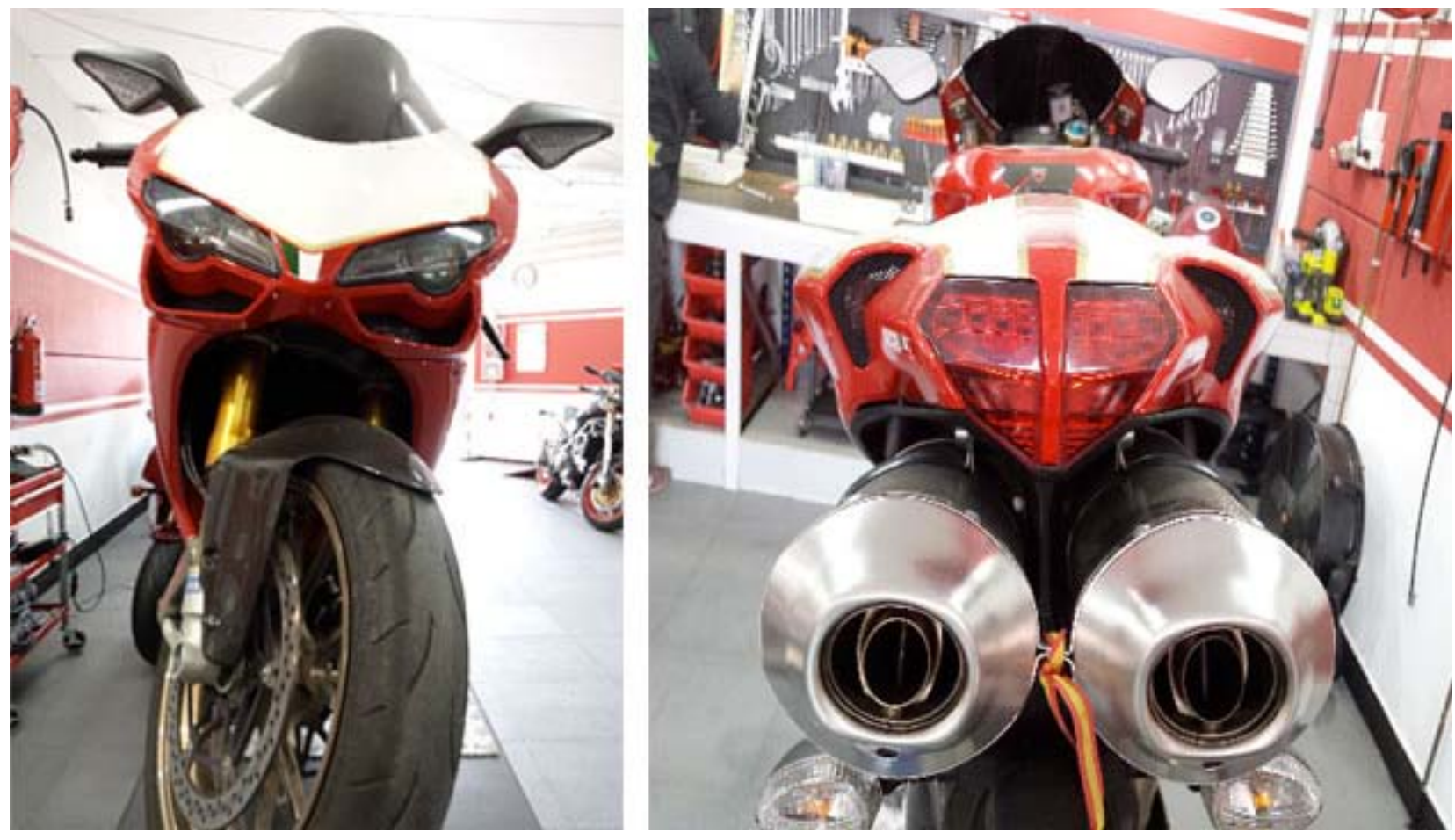

Fig. 14 (izda). Vista del frontal de la 1098. Fig. 15 (dcha). Parte final del asiento de la 1098 de Ducati.

En el año 2008 hizo su aparición la exclusiva DB7 de Bimota. El nombre de esta marca de motocicletas está formado por las iniciales de los apellidos de sus fundadores, siendo estos Bianchi, Morri y el ya mencionado Tamburini.

Bimota pensó que todos los fabricantes de motocicletas seguirían el diseño de la 999, tal y como hicieron con la 916, por eso se basaron en la 999 para la creación de la DB7, probablemente después de varios años de desarrollo del diseño. Este modelo puede verse en las fig. 17 y fig. 18.
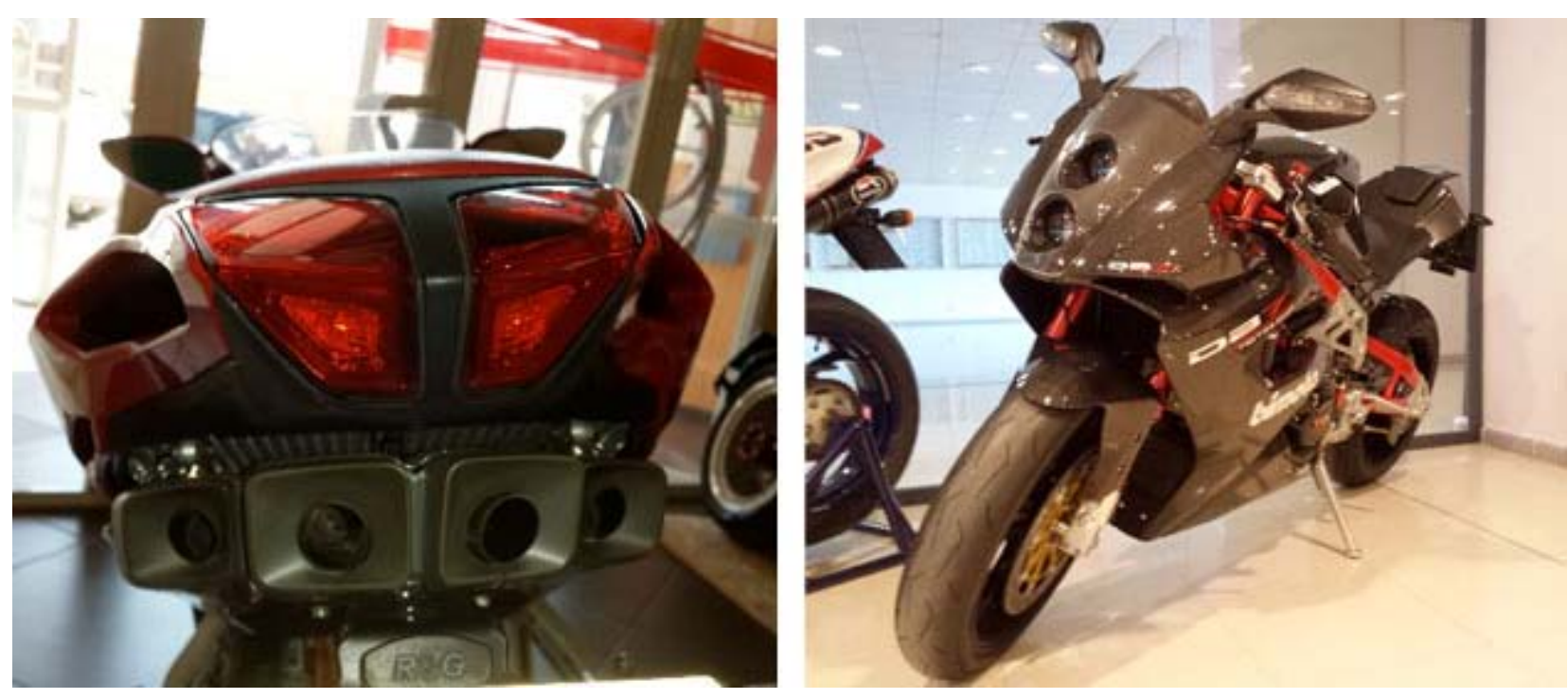

Fig. 16 (izda). Parte final del asiento de la F4 1000. Fig. 17 (dcha). Vista de la Bimota DB7. 
Ya en el año 2009 sale el modelo 1198 de Ducati cuyo diseño es igual al de la 1098. Su versión deportiva 1198 SPS (motor que equipa la DB7 de las imágenes de este artículo haciendo que el modelo que aquí se expone sea único en el mundo) es el tope que se alcanza con el mítico motor Pantah de Ducati. Si se desarrolla el Pantah en su vertiente turismo con el Testastretta $11^{\circ}$ (este ángulo de $11^{\circ}$ hace referencia a los grados de solape de las válvulas) y posteriormente con el DVT.

Las versiones deportivas de Ducati comienzan una nueva etapa con los modelos Panigale. En la fig. 19 se ve la 1199 Panigale S que equipa el motor Super Quadro que tiene un diámetro de pistón mayor que la carrera y desarrolla $195 \mathrm{CV}$, pero el modelo que aparece tiene cambiado los escapes por unos increibles Termignoni que hacen incrementar la potencia hasta los $205 \mathrm{CV}$. El motor de la fig. 20 es el que lleva dentro este modelo 1199, y la firma que se ve en la fig. 21 es la de Carl Fogarty, cuatro veces campeón del mundo de Superbike con Ducati en los años noventa. En esta última figura se aprecia el diseño del tanque de combustible para adaptar lo mejor posible el cuerpo del conductor a la motocicleta, consiguiendo que haya continuidad de la línea del diseño con el cuerpo, favoreciendo que se desdibuje donde empieza una y donde termina el otro.
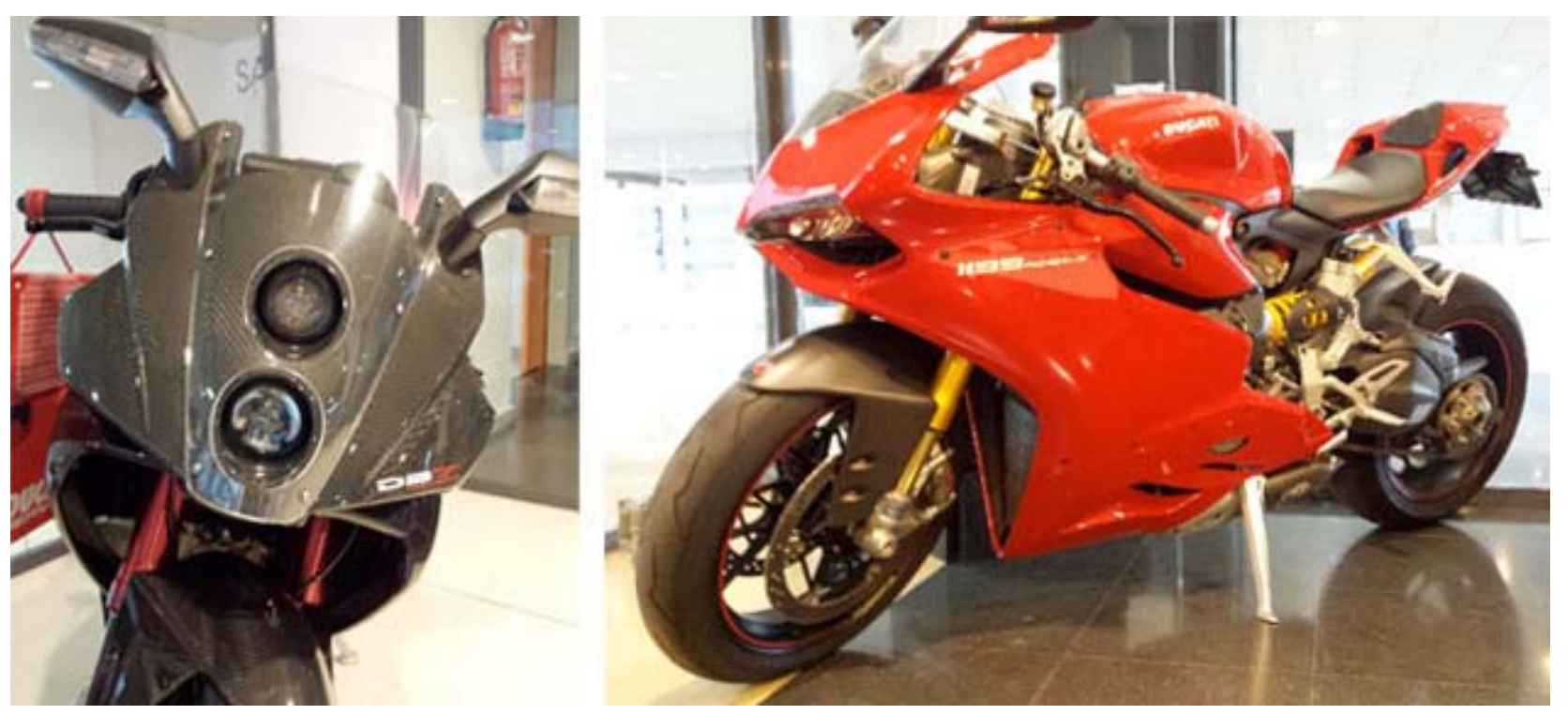

Fig. 18 (izda). Frontal de la Bimota DB7. Fig. 19 (dcha). Ducati 1199 Panigale S.
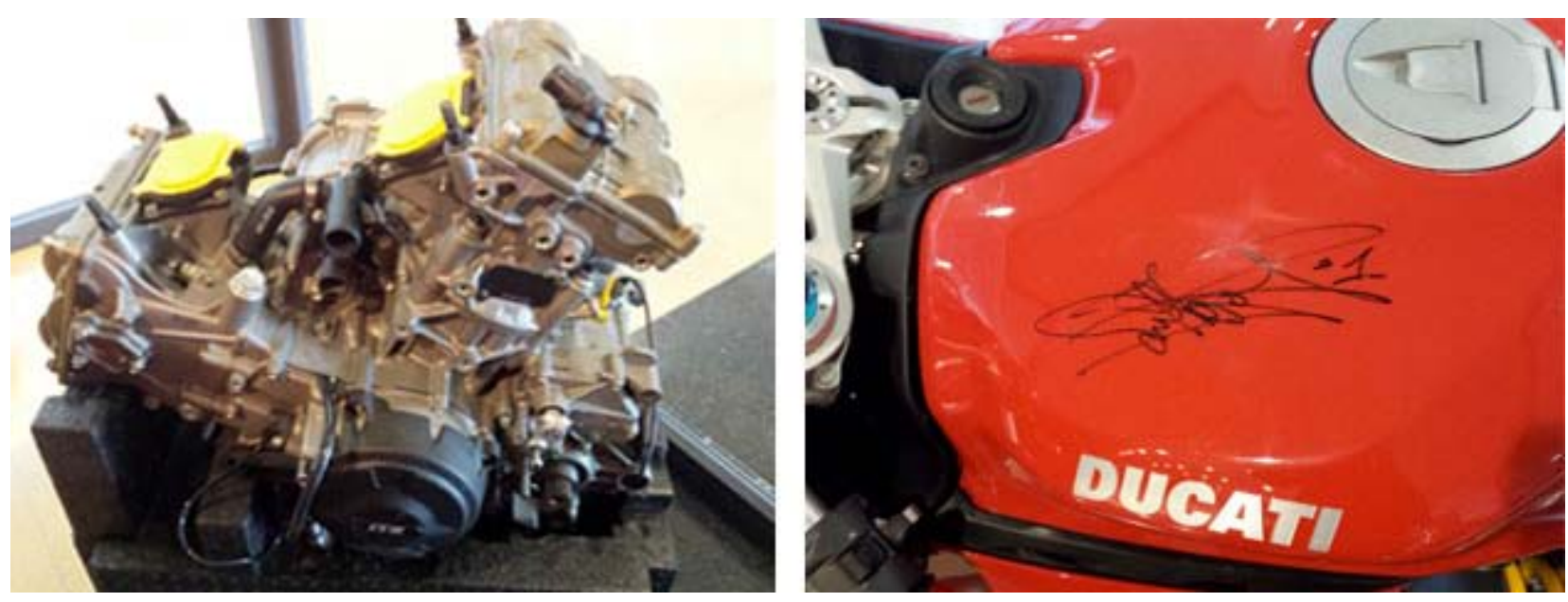

Fig. 20 (izda). Motor que incorpora la 1199. Fig. 21 (dcha). Firma de Carl Fogarty en el tanque de la 1199 Panigale S. 


\section{Conclusiones}

La conclusión que obtiene es que desde que salió al mercado la 916 de Tamburini, y su espectacular y precioso diseño, la intentaron imitar, tanto en sus líneas externas como internamente otros fabricantes de motocicletas. Esta motocicleta fue un referente que ha servido de base para muchos otros modelos que han salido posteriormente. Consiguió una unión entre el diseño de sus líneas junto con el rendimiento mecánico, que es muy complicado de conseguir. Esta observación puede servir para que se abra una línea de investigación que compare modelos de motocicletas que han marcado un antes y un después en su diseño exterior, que muestre cómo ha evolucionado la tendencia de éste a lo largo del tiempo.

La 916 dio paso a la 996, ésta a la 998; el diseño de la 916 evolucionó con la MV Agusta F4 del propio Tamburini; Ducati intentó otro golpe de efecto parecido a la 916 con la 999 y no le salió bien pero a pesar de ello Bimota se basó en ésta última para crear su DB7; Ducati sacó la 1098, con atisbos de mezcla entre su 998 y la F4, etc. Se podrían mencionar otras marcas con sus modelos que intentaron imitar a la 916, pero este artículo no pretende abarcar algo que sería muy complicado de evaluar.

Las líneas de la 916 atraen las miradas allá por donde pasan, y si con palabras se pudiera describir la sensación que se tiene cuando se escuchan sus Termignoni, esas palabras enamorarían a cualquiera que se acercara a sus redes acústicas. A veces no se pueden describir de ninguna forma los sentimientos evocados por algo, y este caso es uno de ellos. Ser ducatista a veces no tiene explicación, y la 916 fue un modelo que creó muchos de esos ducatistas gracias a su icónico diseño. Subirse encima de la 916, arrancarla y sentir su ronroneo, a la vez que uno se deja imbuir de ella, hacerse parte de su diseño, no tiene comparación. Gracias Tamburini por crear la 916. Gracias por ser un genio que ha dejado tantas genialidades que serán para siempre.

\footnotetext{
*Ingeniero Técnico Industrial especialidad Mecánica, Ingeniero Técnico en Diseño Industrial, Máster Oficial en Prevención de Riesgos Laborales, Experto Universitario en Innovación y Tecnología Educativa, Colaborador en el programa "Las 101 mañanas" de 101TV, organizador y ponente de la Conferencia "Diseño y Mecánica Ducati" en la Escuela Politécnica Superior de la Universidad de Málaga. Correo: masakari357@gmail.com

${ }^{1}$ Gracias a Jorge J. Moreno Pérez, de Ducati Moto1000 en Málaga, por su aportación a este artículo, ya que sin él no hubiera sido posible realizarlo.

${ }^{2}$ BROWN, Roland (adaptación: Bartolomé, Laura). Motos de leyenda. La revolucionaria Ducati 916. 2014.

<http://solomoto.es/872/1398669250/actualidad/motos-de-leyenda-la-revolucionaria-ducati-916> (12.03.16)

3 WIEHAGER, Hans-Joachim./GAßEBNER, Jürgen. Ducati. Pasión sobre ruedas, NGV, Colonia (Alemania) 2010, p. 58.
}

\section{IMÁGENES}

Todas las imágenes que aparecen en este artículo están hechas por el autor de este artículo, siendo de su propiedad.

Revista internacional de investigación, innovación y desarrollo en Diseño • ISSN 1889-433 x 